DOI: https://doi.org/10.47405/mjssh.v5i11.559

\begin{tabular}{|c|c|}
\hline S & Malaysian Journal of Social Sciences and Humanities (MJSSH) \\
\hline Malaysian Journal of & Volume 5, Issue 11, November 2020 \\
\hline (MJ-sSH) & e-ISSN : 2504-8562 \\
\hline & $\begin{array}{l}\text { Journal home page: } \\
\text { www.msocialsciences.com }\end{array}$ \\
\hline
\end{tabular}

\title{
Faktor Penglibatan Pelajar dalam Aktiviti Bukan Akademik anjuran Universiti
}

\author{
Nazriah Rasul', Rafiza Mohamed', Siti Nurhuda Abd. Wahid', Yusmady Md. Junus', \\ Rosmiza Awang Noh ${ }^{1}$ \\ 1Pusat Pengajian Diploma (PPD) SPACE, Universiti Teknologi Malaysia Kuala Lumpur (UTMKL)
}

Correspondence: Nazriah Rasul (nazriah@utmspace.edu.my)

\begin{abstract}
Abstrak
Aktiviti-aktiviti yang dianjurkan di universiti tidak kira akademik atau bukan akademik haruslah boleh membentuk pelajar yang seimbang bukan sahaja dari aspek jasmani dan emosi, malah dari aspek rohani dan intelek juga. Walau bagaimanapun, trend terkini pelajar adalah kurang melibatkan diri dalam aktiviti-aktiviti anjuran universiti Oleh itu kajian ini bertujuan untuk mengenal pasti faktor penglibatan pelajar dalam aktiviti bukan akademik anjuran universiti dan mengenal pasti langkahlangkah yang boleh diambil supaya lebih ramai pelajar melibatkan diri dalam aktiviti bukan akademik anjuran universiti. Ia dijalankan terhadap 888 orang responden daripada 5,534 pelajar diploma di Universiti Teknologi Malaysia Kuala Lumpur (UTMKL). Berdasarkan kepada keputusan analisa menggunakan kaedah Relative Importance Index (RII), faktor pengaruh rakan telah dikenal pasti sebagai faktor yang paling mempengaruhi penglibatan pelajar terhadap aktiviti bukan akademik anjuran universiti iaitu dengan nilai RII sebanyak 0.79. Manakala faktor yang paling kurang mempengaruhi pelajar menyertai aktiviti bukan akademik anjuran universiti ialah faktor personaliti pelajar dengan nilai $R I I$ sebanyak 0.59. Maklum balas daripada pelajar berkenaan dengan langkahlangkah yang boleh diambil supaya lebih ramai pelajar melibatkan diri dalam aktiviti bukan akademik anjuran universiti dianalisis menggunakan kaedah Analisa Bertema. Maklum balas pelajar telah dikelaskan kepada 6 tema iaitu penambahan aktiviti yang aktif dan menarik, penambahan infrastruktur oleh universiti, menambah baik saluran komunikasi pelaksanaan aktiviti, merancang pelaksanaan aktiviti, sokongan universiti dalam bentuk kewangan dan memberikan galakan dan motivasi. Hasil daripada kajian ini boleh diguna pakai dalam membuat perancangan aktiviti akademik di universiti bagi menarik lebih ramai pelajar melibatkan diri. Kajian seperti ini harus dijalankan pada masa akan datang. Perincian mengikut jenis aktiviti bukan akademik dan perbandingan mengikut jantina terhadap faktor-faktor yang mempengaruhi penglibatan pelajar terhadap aktiviti bukan akademik dapat membantu dalam menjelaskan dan memperincikan lagi penglibatan para pelajar dengan lebih menyeluruh.
\end{abstract}

Kata kunci: penglibatan pelajar, aktiviti bukan akademik, relative importance index, analisa bertema

\section{Factors of Student Involvement in Non-Academic Activities Organised by the University}

\begin{abstract}
Activities organised at the university regardless of academic or non-academic, should be able to develop balanced students in terms of physical and emotional aspects, as well as the spiritual and intellectual aspects. However, the current trend is students are less involved in activities organised by a
\end{abstract}


university. Therefore, this study aims to identify factors influencing student involvement in nonacademic activities organised by the university; it also intends to identify potential measures for more students' engagement in non-academic activities organised by the university. The study was conducted on 888 respondents out of 5,534 diploma students at Universiti Teknologi Malaysia Kuala Lumpur (UTMKL). Based on the results of the analysis using the Relative Importance Index (RII) method, peer influence factor has been identified as the most significant factor that influenced students' involvement in non-academic activities organised by the university, with an RII value of 0.79. Meanwhile, the least influencing factor for students' participation in non-academic activities organised by the university is the students' personality factor, with an RII value of 0.59 . Feedback from students regarding the feasible steps so that more students would get involved in non-academic activities organised by the university is analysed using the Themed Analysis method. Students' feedback is classified into six themes, namely additional of active and attractive activities, increased infrastructure by the university, improve communication channels of activities implementation, plan the implementation of activities, and university support in terms of financial, encouragement, and motivation. The results of this study can be used in planning academic activities at the university to attract more students' involvement. Similar studies should be conducted in the future. Details on the types of non-academic activities and comparison based on gender regarding factors influencing students' involvement in non-academic activities could help in explaining and further specifying students' participation comprehensively.

Keywords: students' involvement, non-academic activities, relative importance index, thematic analysis

\section{Pengenalan}

Dalam Pelan Pembangunan Pendidikan Malaysia 2015-2025, terdapat 10 lonjakan diperkenalkan dengan tujuan untuk menghasilkan prestasi pendidikan yang lebih unggul kepada mahasiswa, mewujudkan amalan terbaik sistem pendidikan yang mampu melahirkan bakat yang berkualiti serta menerapkan proses pembelajaran mengikut trend global dengan penggunaan teknologi (Pelan Pembangunan Pendidikan Malaysia 2015 - 2025, 2015). Sejajar dengan pembangunan, universiti pada masa kini turut mengalami perubahan sehingga menjadi sesebuah institusi yang lebih kompleks bagi mewujudkan satu persekitaran pendidikan yang lebih kondusif dan menggalakkan pendidikan yang kompetitif (Kardi, 2011).

Sistem sesebuah universiti juga lebih teratur dan sistematik sekali gus membenarkan pelaksanaan pelbagai variasi aktiviti sama ada di dalam atau di luar kawasan universiti sama ada berbentuk akademik mahupun bukan akademik. Berpandukan kepada 10 lonjakan ini, aktiviti-aktiviti yang dianjurkan di universiti adalah bertujuan untuk membentuk pelajar yang seimbang dari aspek jasmani, emosi, rohani dan intelek (Mohamed, 2014). Aktiviti akademik sememangnya merupakan elemen wajib dalam kamus seorang pelajar. Pelajar perlu menimba ilmu pengetahuan mengikut bidang yang diceburi untuk kegunaan pada masa hadapan. Selain itu, aktiviti bukan akademik yang dikendalikan oleh universiti turut memainkan peranan yang penting dalam membentuk peribadi pelajar. Hal ini termasuklah menimba ilmu dengan lebih mendalam mengenai bidang yang diceburi serta mengasah kemahiran dan sifat kepimpinan dalam seseorang mahasiswa.

Walau bagaimanapun, ada segelintir pelajar berpendapat bahawa penglibatan pelajar dalam aktiviti bukan akademik yang dianjurkan oleh pihak universiti ini membuang masa dan tidak mendatangkan sehingga mengakibatkan penunjuk prestasi utama universiti tidak mencapai sasaran yang dirancang. Maka, kajian ini dijalankan untuk mengenal pasti faktor-faktor yang mempengaruhi penglibatan pelajar dalam aktiviti bukan akademik anjuran universiti dan mengenal pasti langkah-langkah yang boleh diambil supaya lebih ramai pelajar melibatkan diri dalam aktiviti bukan akademik anjuran pihak universiti. 


\section{Sorotan Literatur}

Pelaksanaan aktiviti bukan akademik oleh para pelajar boleh dipengaruhi oleh faktor luaran dan faktor dalaman. Faktor luaran dan dalaman ini merangkumi faktor personaliti pelajar, faktor motivasi pelajar, faktor kewangan keluarga, faktor sokongan keluarga, faktor pengaruh rakan, faktor sokongan universiti dan faktor infrastruktur universiti.

Sifat dan personaliti bagi seseorang individu adalah berbeza antara satu sama lain. Pelajar biasanya akan menilai terlebih dahulu kelebihan dan kekurangan yang terdapat pada diri masing-masing sebelum memutuskan sama ada mahu melibatkan diri ataupun tidak dengan aktiviti bukan akademik anjuran universiti (Othman \& Jasni, 2016). Bagi sesetengah pelajar, mereka mempunyai personaliti yang agak skeptikal terhadap keberkesanan pelaksanaan aktiviti bukan akademik anjuran pihak universiti ini. Mereka beranggapan bahawa aktiviti sebegini hanya membuang masa dan tidak begitu penting untuk masa hadapan. Sebaliknya, masa yang ada tersebut adalah lebih baik digunakan untuk mengulang kaji pelajaran agar dapat memperoleh keputusan yang cemerlang dalam pembelajaran (Aminuddin, 2004). Selain personaliti, penglibatan pelajar dalam aktiviti bukan akademik anjuran pihak universiti turut dipengaruhi oleh motivasi pelajar itu sendiri. Pelajar lebih bermotivasi sekiranya aktiviti yang disertai dapat membantu mereka dalam bidang pekerjaan yang ceburi selepas bergraduasi (Denault \& Guay, 2017).

Faktor kewangan keluarga turut menjadi peranan utama yang mempengaruhi penglibatan pelajar dalam aktiviti bukan akademik anjuran universiti. Kebanyakan pelajar terdiri daripada golongan yang masih belum bekerja maka sudah pasti mereka tidak mempunyai sumber kewangan sendiri untuk menampung kos aktiviti yang mereka sertai. Ini menyebabkan ibu bapa perlu campur tangan dari segi pembiayaan dan kewangan dalam urusan penglibatan anak-anak mereka (Jian $\mathrm{Xu}, 2017$ ). Oleh itu, bagi pelajar yang mempunyai latar belakang sosioekonomi yang rendah, mereka mempunyai kecenderungan yang lebih rendah untuk melibatkan diri dalam aktiviti bukan akademik anjuran universiti (Coulangeon, 2018).

Seterusnya, kebanyakan pelajar sering menyertai aktiviti bukan akademik di universiti bersama-sama dengan rakan sebaya kerana mereka berasa kurang yakin sekiranya mahu menyertai aktiviti sedemikian secara berseorangan (Othman \& Jasni, 2016). Didapati ada pelajar berminat untuk menyertai aktiviti bukan akademik di universiti tersebut kerana aktiviti sedemikian dilihat sebagai platform untuk membina jalinan persahabatan yang baharu bersama rakan-rakan lain (Villalobos, et al., 2016). Selain itu ada sesetengah pelajar melihat penyertaan bahawa aktiviti bukan akademik seperti aktiviti tambahan sebagai peluang untuk mereka bersosial (Al-Ansari, et al., 2016).

Di samping itu, para pelajar dilihat mampu untuk menguruskan masa dengan lebih baik jika terlibat dengan aktiviti bukan akademik seperti aktiviti kokurikulum yang tersusun dan lebih berstruktur (Coulangeon, 2018). Impak positifnya adalah kebanyakan aktiviti bukan akademik yang dijalankan di universiti adalah berstruktur yang berupaya membina keterampilan diri, memupuk nilai-nilai positif, menggalakkan kerja berkumpulan dan mampu menangani masalah dalam situasi yang mencabar (Othman \& Jasni, 2016). Walau bagaimanapun, masih terdapat sesetengah universiti yang tidak cakna lagi akan hal ini. Dalam masa yang sama, infrastruktur universiti turut perlu dipastikan mencukupi serta selamat digunakan. Ini termasuklah persekitaran pelajar, lokasi kemudahan sukan, maklumat berkaitan aktiviti yang akan dijalankan dan lain-lain (Ismail \& Muhammad, 2015). Kemudahan infrastruktur yang bagus juga boleh menghilangkan stress serta dapat menyediakan persekitaran aktiviti yang kondusif (Adejompo, 2017).

\section{Metodologi}

Kajian ini dijalankan terhadap pelajar-pelajar diploma daripada 14 program di bawah 4 jabatan di Pusat Pengajian Diploma (PPD) Universiti Teknologi Malaysia Kuala Lumpur (UTMKL). Jumlah populasi pelajar adalah seramai 5,534 orang. Terdapat 888 orang responden telah memberikan maklum balas terhadap borang soal selidik yang telah diedarkan secara rawak kepada para pelajar. 


\section{Instrumen}

Instrumen yang telah direka bentuk mengandungi 3 bahagian yang wajib dijawab oleh setiap pelajar iaitu bahagian A, B dan C. Bahagian A merupakan soalan berkenaan demografi responden seperti jantina, nama program serta kohort pelajar. Bahagian B pula mengandungi soalan-soalan yang perlu dijawab oleh responden mengikut kecenderungan mereka terhadap faktor-faktor yang mempengaruhi penglibatan mereka dalam aktiviti-aktiviti bukan akademik anjuran universiti. Ia direka bentuk berdasarkan kepada skala Likert empat tahap di mana tahap 1 ialah tahap tidak setuju, tahap 2 adalah tahap kurang setuju, tahap 3 adalah tahap setuju manakala tahap 4 adalah tahap sangat setuju. Bahagian C pula terdiri daripada soalan berbentuk soalan terbuka di mana responden memberi cadangan penambahbaikan dari perspektif mereka.

\section{Pengumpulan data}

Instrumen kajian yang telah diedarkan kepada responden adalah berbentuk google form. Semua maklum balas yang diperoleh telah dianalisis bagi mencapai objektif kajian yang telah digariskan di awal kajian iaitu mengenal pasti faktor-faktor yang mempengaruhi penglibatan pelajar dalam aktiviti bukan akademik anjuran universiti dan mengenal pasti langkah-langkah yang boleh diambil supaya lebih ramai pelajar melibatkan diri dalam aktiviti bukan akademik anjuran pihak universiti.

Saiz sampel kajian pula ditentukan menggunakan perisian Raosoft. Perisian ini telah diguna pakai secara meluas oleh pengkaji di bidang sains sosial untuk mengira dan menganggarkan secara saintifik bilangan sampel suatu kajian. Berdasarkan pengiraan yang dibuat oleh Raosoft terhadap 5534 orang pelajar dari 14 program di PPD UTM Kuala Lumpur iaitu setelah mengambil kira pencapaian sehingga 95\% paras kejituan dan 5\% kesilapan (Curtis \& Curtis, 2011), maka, bilangan responden yang diperlukan adalah seramai 360 pelajar (Rajah 1). Namun, kajian melibatkan penyertaan responden yang jauh lebih tinggi iaitu seramai 888 orang di mana melebihi cadangan oleh Raosoft.

\section{Rajah 1: Pengiraan Saiz Sampel Kajian Menggunakan Perisian Raosoft}

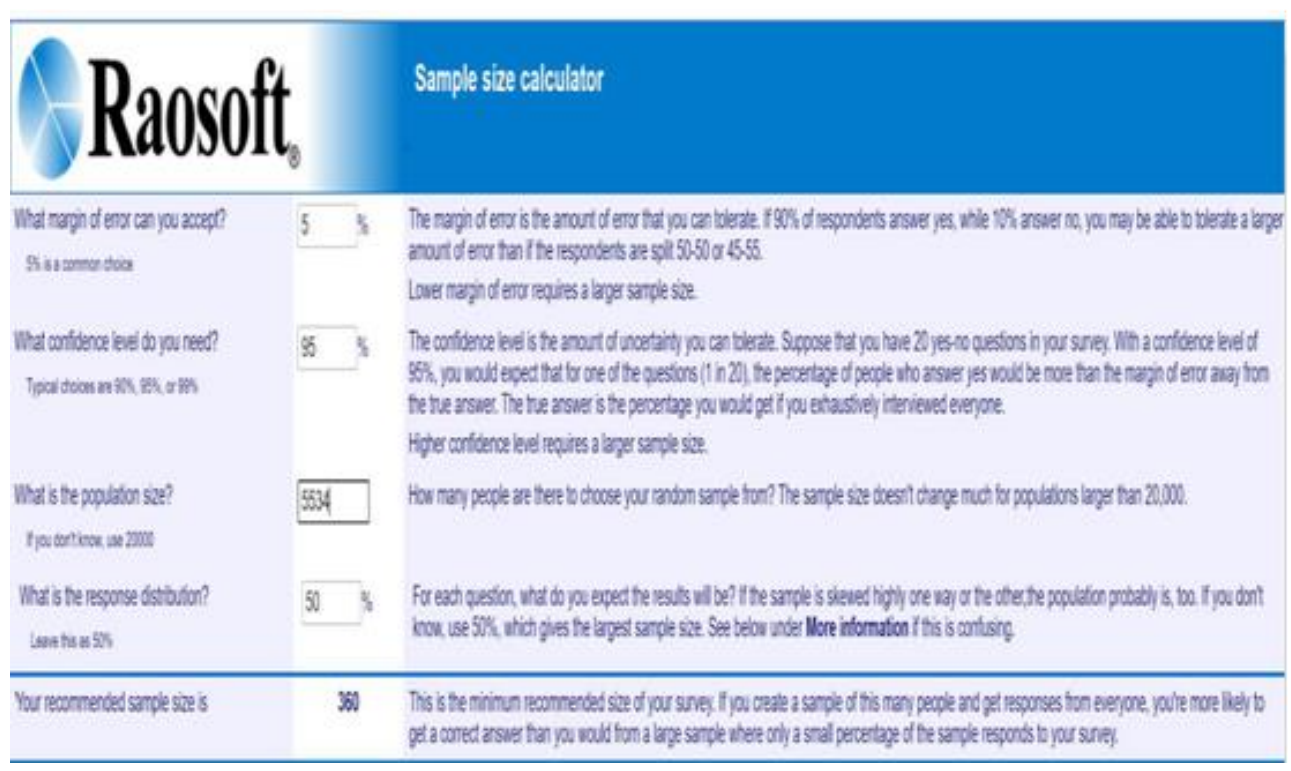

\section{Analisa data}

Bahagian ini menerangkan cara data-data yang diperoleh dari instrumen kajian dianalisis bagi mencapai objektif yang telah dikenal pasti terlebih dahulu di awal kajian. Data daripada responden yang diperoleh dari bahagian $B$ instrumen kajian, dianalisis dengan menyusun 7 faktor yang telah dikenal pasti dalam kajian literatur mengikut kecenderungan pemilihan pelajar dalam melibatkan diri dengan aktiviti-aktiviti bukan akademik anjuran universiti. Kaedah Relative Importance Index [RII] 
DOI: https://doi.org/10.47405/mjssh.v5i11.559

digunakan untuk menyusun faktor-faktor ini (Lim \& Alum, 1995). Rumus RII adalah seperti ditunjukkan di dalam rajah 2 berikut.

Rajah 2 : Rumus Relative Importance Index [RII] (Lim \& Alum, 1995)

$$
R I I=\frac{4 n 1+3 n 2+2 n 3+1 n 4}{4 N}
$$

Berdasarkan rajah 2, n1 adalah bilangan responden yang menjawab sangat setuju, $\mathrm{n} 2$ adalah bilangan responden yang menjawab setuju, n3 adalah bilangan responden yang menjawab tidak setuju, n4 adalah bilangan responden yang menjawab sangat tidak setuju dan $\mathrm{N}$ pula adalah bilangan responden. Daripada rumus RII, nilai indeks setiap faktor dapat dikenal pasti dan disusun mengikut keutamaan.

Cadangan daripada responden yang diperoleh dari bahagian $\mathrm{C}$ instrumen kajian pula dianalisis menggunakan kaedah Analisa Bertema (Rajah 3). Kaedah Analisa Bertema adalah kaedah yang digunakan untuk mengenal pasti dan menganalisis maklumat berdasarkan data yang dikumpulkan (Braun \& Clarke, 2006). Proses ini bermula dengan mengumpul dan Menyusun data-data yang telah diperoleh, menganalisis corak data tersebut secara keseluruhan dan mengklasifikasikan data-data tersebut mengikut tema-tema atau corak-corak yang dikehendaki (Gavin, 2008).

Rajah 3 : Fasa-fasa Analisa Bertema

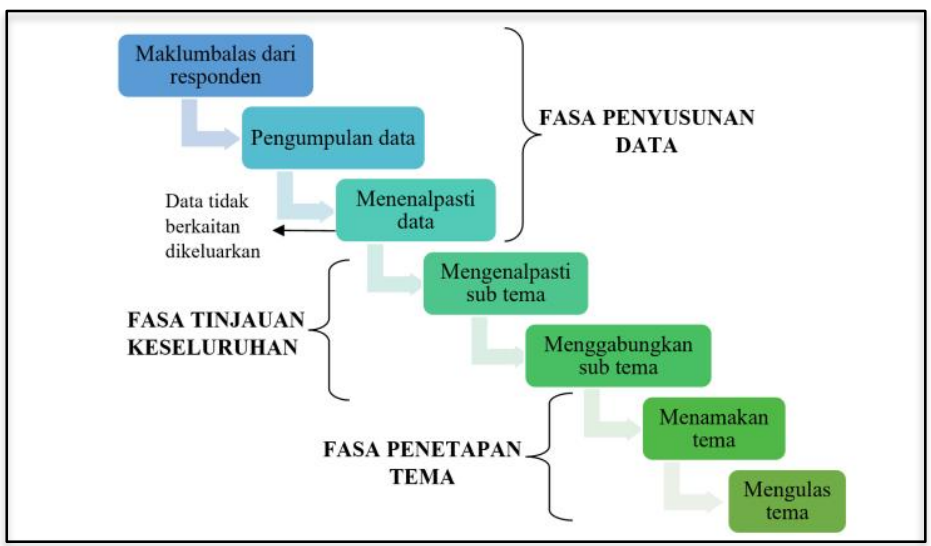

\section{Hasil Kajian dan Perbincangan}

Dapatan daripada instrumen yang diperoleh daripada responden dianalisis berdasarkan kepada objektif yang telah ditetapkan di awal kajian.

\section{Analisa profil responden}

Seramai 888 orang pelajar telah terlibat sebagai responden dalam kajian ini. Daripada jumlah tersebut, terdapat seramai $57 \%$ adalah responden wanita manakala responden lelaki pula seramai $43 \%$. Jumlah responden teramai adalah daripada program DDWC dan DDWQ dengan jumlah seramai 173 responden (20\%) dan 154 responden (18\%). Manakala program DDWB mempunyai bilangan responden yang paling rendah iaitu hanya melibatkan 5 responden $(0.6 \%)$ daripada keseluruhan responden kajian (Rajah 4). 


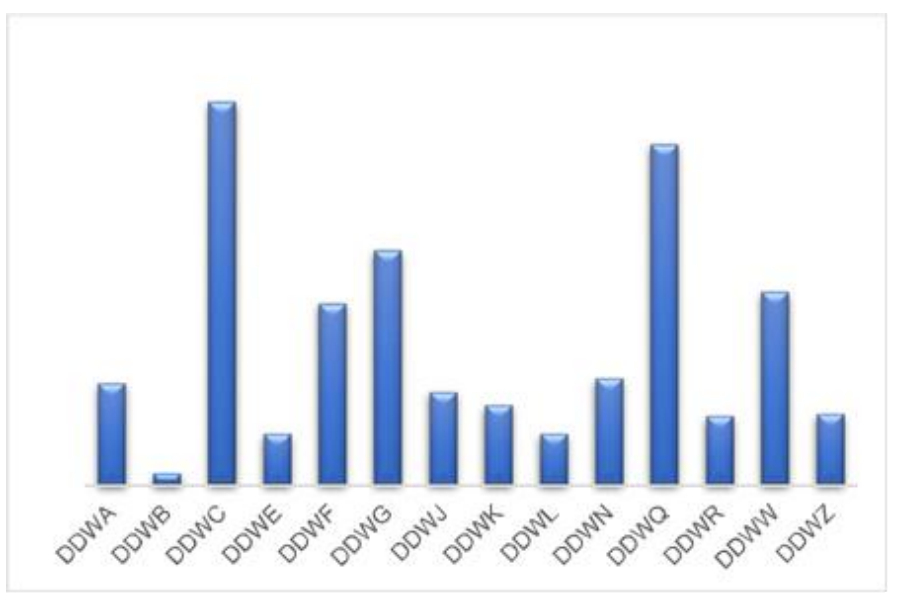

\section{Analisa faktor-faktor yang mempengaruhi penglibatan pelajar terhadap program bukan akademikanjuran universiti}

Faktor yang mempengaruhi penglibatan pelajar terhadap program bukan akademik anjuran universiti, kaedah analisa data Relative Importance Index (RII) telah diguna pakai. Bagi faktor dengan nilai RII menghampiri 1.0, faktor tersebut dianggap mempunyai keutamaan yang lebih tinggi berbanding dengan faktor yang mempunyai nilai RII menghampiri 0.0 (Lim \& Alum, 1995). Analisa RII adalah seperti yang ditunjukkan dalam jadual 1.

Jadual 1: Rumusan Faktor Penglibatan Pelajar Dalam Aktiviti Bukan Akademik

\begin{tabular}{lrc}
\hline \multicolumn{1}{c}{ Faktor } & Nilai rii & Keutamaan \\
\hline Personaliti pelajar & 0.59 & 6 \\
Motivasi pelajar & 0.68 & 4 \\
Kewangan keluarga & 0.68 & 4 \\
Sokongan keluarga & 0.67 & 5 \\
Pengaruh rakan & $\mathbf{0 . 7 9}$ & $\mathbf{1}$ \\
Sokongan universiti & 0.73 & 3 \\
Infrastruktur universiti & 0.76 & 2 \\
\hline
\end{tabular}

Berdasarkan kepada keputusan analisa RII, faktor pengaruh rakan telah dikenal pasti paling mempengaruhi penglibatan pelajar (nilai $R I I=0.79$ ). Pelajar lebih berminat untuk mengikuti programprogram secara beramai-ramai. Dengan cara ini, mereka boleh menjadikan penyertaan aktiviti-aktiviti bukan akademik ini sebagai platform untuk mereka memulakan hubungan dengan rakan yang baharu (Villalobos, et al., 2016). Seterusnya, mereka juga boleh berkongsi minat atau kegemaran yang sama (Al-Ansari, et al., 2016).

Faktor kedua ialah faktor infrastruktur universiti (nilai $R I I=0.76$ ) dan faktor sokongan universiti menjadi keutamaan yang ketiga dengan nilai RII sebanyak 0.73. Pelajar lebih berminat untuk melibatkan diri dengan aktiviti bukan akademik sekiranya infrastruktur yang disediakan oleh universiti adalah mencukupi serta selamat digunakan seperti kemudahan persekitaran pelajar, lokasi kemudahan sukan, maklumat berkaitan aktiviti yang akan dijalankan dan lain-lain (Ismail \& Muhamad, 2015). Sekiranya pihak universiti sentiasa menyokong penglibatan pelajar ini, ia juga akan dapat menyerlahkan nilai dan bakat yang tersembunyi (Osman \& Jasni, 2016).

Manakala faktor motivasi pelajar dan kewangan keluarga berada pada keutamaan yang keempat dengan nilai $R I I 0.68$, diikuti dengan faktor sokongan keluarga (nilai $R I I=0.67$ ) dan akhir sekali adalah faktor personaliti pelajar dengan nilai $R I I$ 0.59. Ada segelintir pelajar berpendapat bahawa melalui aktiviti bukan akademik ini, mereka menjadi seronok untuk mempelajari ilmu baharu serta 
yakin bahawa penglibatan mereka dalam aktiviti sebegini akan dapat membantu mereka untuk menceburi sektor pekerjaan yang mereka minati pada masa depan kelak (Denault \& Guay, 2017). Ada sesetengah pelajar merasakan bahawa sokongan keluarga adalah penting. Dorongan dari keluarga terutamanya dari ibu bapa dapat mempengaruhi pelajar menyertai aktiviti-aktiviti bukan akademik. Walau bagaimanapun, terdapat sesetengah ibu bapa yang tidak mengambil peduli dengan penglibatan anak-anak mereka dalam aktiviti bukan akademik dan hanya membenarkan mereka untuk mempelajari subjek-subjek akademik sahaja. Hal ini kerana, mereka menganggap bahawa aktiviti sebegini kurang penting untuk penentuan masa hadapan anak-anak mereka sebagai seorang pelajar (Agus, 2016). Personaliti pelajar pula adalah berbeza-beza antara satu sama lain. Ada sesetengah pelajar dapat menilai kelebihan dan kekurangan yang ada pada diri sendiri dan personaliti mereka terlebih dahulu (Osman \& Jasni, 2016). Oleh itu, dengan penglibatan mereka dalam aktiviti-aktiviti bukan akademik ini boleh mempengaruhi mereka dalam membendung kekurangan mereka.

\section{Analisa cadangan penambahbaikan pelaksanaan program bukan akademik anjuran universiti}

Bagi analisa cadangan penambahbaikan yang dikemukakan oleh responden, kaedah Analisa Bertema telah diguna pakai. Cadangan-cadangan tersebut ditelusuri satu-persatu dan telah dikelaskan kepada beberapa tema iaitu penambahan aktiviti yang aktif dan menarik, menambahbaikkan infrastruktur, menambahbaikkan saluran komunikasi, perancangan masa pelaksanaan aktiviti, menyediakan peruntukan serta memberikan galakan dan motivasi.

Majoriti responden mencadangkan tema penambahan aktiviti yang aktif dan menarik seperti memperbanyakkan aktiviti sukan. Cadangan ini termasuklah aktiviti sukan secara normal seperti memanah, bowling dan softball serta aktiviti sukan secara dalam talian seperti e-sport. Selain itu, penambahan aktiviti yang berkaitan teknikal turut dicadangkan dalam kajian ini. Terdapat sekumpulan responden yang mencadangkan agar pihak universiti menambah aktiviti yang boleh menggilap bakat para pelajar seperti seni muzik moden dan klasik. Cadangan penambahan aktiviti seperti ini boleh menggilap bakat pelajar yang sememangnya penting memandangkan kebolehpasaran seseorang graduan juga bergantung kepada bakat yang mereka miliki dan pelajari (Nor, et al., 2017). Ada segelintir pelajar yang mencadangkan agar aktiviti bukan akademik perlu dianjurkan di luar kawasan universiti, melaksanakan aktiviti lawatan sambil belajar serta menganjurkan aktiviti-aktiviti yang lebih menarik seperti perkhemahan. Pertambahan aktiviti ini dapat memberikan lebih banyak kesan positif dan sekali gus meningkatkan prestasi individu dalam melakukan sebarang aktiviti (Tews et al., 2013).

Bagi tema menambah baik infrastruktur, ada pelajar mencadangkan agar bilangan peralatan aktiviti dapat ditambah. Cadangan ini dapat memberikan semangat di kalangan pelajar untuk melibatkan diri dalam sebarang aktiviti yang dianjurkan oleh pihak universiti (Taiwo, 1998). Pada masa yang sama, terdapat juga responden yang membanding bezakan antara kemudahan infrastruktur di UTM Johor Bahru (UTMJB) yang serba lengkap berbanding dengan UTM Kuala Lumpur (UTMKL).

Bagi tema menambah baik saluran komunikasi, terdapat responden yang mencadangkan agar pihak universiti memperbaiki kaedah penyebaran maklumat mengenai aktiviti bukan akademik yang akan dijalankan di universiti dengan cara menggunakan medium media sosial. Ini dapat menjamin maklumat mengenai pelaksanaan aktiviti bukan akademik tersebut sampai kepada semua pelajar. Komunikasi yang bagus adalah diperlukan oleh mana-mana organisasi untuk kekal cekap dan terus berkembang (Meluso, 2020). Ada juga responden juga mencadangkan agar pihak universiti tidak bersikap pilih kasih dalam memilih jawatankuasa pelaksana aktiviti bukan akademik. Sebaiknya, ia perlu dikomunikasikan dengan semua pelajar.

Bagi tema perancangan masa pelaksanaan aktiviti pula, majoriti responden mencadangkan agar aktiviti bukan akademik dapat dilaksanakan pada waktu hujung minggu sahaja atau pada waktu-waktu selain waktu akademik supaya masa pembelajaran mereka tidak terganggu. Pengurusan masa yang baik dan cekap amat diperlukan supaya organisasi sentiasa cemerlang (Kumar \& Aithal, 2019). 
Responden juga telah memberi cadangan berdasarkan tema penyediaan peruntukan. Antara cadangan yang telah dikemukakan seperti pihak universiti perlu untuk menyediakan tajaan kewangan bagi menggalakkan lebih ramai lagi pelajar berminat untuk menyertai aktiviti bukan akademik yang dianjurkan (Mahani \& Suraiya, 2020). Selain itu, pihak universiti juga dicadangkan agar menelusuri bajet kewangan terlebih dahulu dan memastikan agar peruntukan untuk aktiviti yang ingin dijalankan telah mencukupi demi mengelakkan para pelajar daripada terpaksa mengeluarkan duit poket sendiri semata-mata untuk menyertai aktiviti-aktiviti yang dianjurkan tersebut.

Di samping itu, di bawah tema galakan dan motivasi, terdapat responden yang mencadangkan agar sistem merit sedia ada di universiti ditambah baik serta memberikan hadiah atau saguhati kepada pelajar yang telah turut serta dalam aktiviti bukan akademik yang telah dianjurkan. Secara psikologinya, galakan dan motivasi ini boleh menjadi sebab dan alasan untuk seseorang individu melakukan sesuatu perkara (Canossa, et al., 2013). Selain itu, dicadangkan juga agar pihak universiti menggalakkan semua pelajar untuk menjadi ketua program dan tidak hanya mengharapkan orang yang sama setiap tahun serta memastikan aktiviti yang dijalankan boleh memupuk keyakinan diri di samping menambah kenalan baru.

\section{Kesimpulan}

Kajian ini telah dijalankan ke atas para pelajar dari 14 program diploma di Universiti Teknologi Malaysia Kuala Lumpur (UTMKL) dengan tujuan untuk mengenal pasti faktor-faktor yang mempengaruhi penglibatan pelajar terhadap aktiviti-aktiviti bukan akademik anjuran universiti dan mengenal pasti langkah- langkah yang boleh diambil supaya lebih ramai pelajar melibatkan diri dalam aktiviti bukan akademik anjuran pihak universiti. Kajian ini dilaksanakan dengan menganalisa instrumen kajian berbentuk soal selidik secara skala Likert menggunakan kaedah Relative Importance Index (RII) bagi mencapai objektif pertama dan kaedah Analisa Bertema bagi mencapai objektif kedua.

Didapati para pelajar lebih memilih faktor pengaruh rakan sebagai faktor yang paling mempengaruhi mereka untuk melibatkan diri dalam aktiviti bukan akademik anjuran universiti iaitu dengan nilai $R I I$ sebanyak 0.79. Para pelajar lebih berminat mengikuti aktiviti bukan akademik secara berkumpulan dengan rakan-rakan yang lain kerana ia boleh menjadikan mereka lebih berkeyakinan untuk melaksanakan setiap program yang dianjurkan. Selain itu, ia juga boleh menjadi platform kepada para pelajar untuk memulakan hubungan dengan rakan sebaya yang baharu. Manakala faktor yang paling kurang mempengaruhi pelajar menyertai aktiviti bukan akademik anjuran universiti adalah faktor personaliti pelajar. Nilai RII bagi faktor personaliti pelajar adalah sebanyak 0.59. Ada sesetengah pelajar tidak begitu mengambil perhatian untuk menyertai aktiviti bukan akademik kerana beranggapan bahawa aktiviti sebegini akan mengganggu konsentrasi pembelajaran mereka. Di samping itu, terdapat juga segelintir pelajar yang menganggap bahawa masa yang digunakan untuk aktiviti bukan akademik ini adalah lebih sesuai sekiranya digunakan untuk menjalankan aktiviti pembelajaran berasaskan akademik. Tambahan lagi, ada juga segelintir pelajar berandaian bahawa aktiviti bukan akademik ini tidak memberi jaminan terhadap masa depan mereka.

Berdasarkan hasil analisa RII juga, tiga faktor utama yang mempengaruhi penglibatan pelajar boleh diklasifikasikan sebagai faktor luaran iaitu pengaruh rakan, infrastruktur universiti dan sokongan universiti. Faktor sokongan dan faktor status kewangan keluarga tidak begitu memberi pengaruh terhadap penglibatan pelajar dalam aktiviti bukan akademik. Manakala faktor motivasi dan personaliti pelajar boleh diklasifikasikan sebagai faktor dalaman. Didapati ia kurang mempengaruhi penglibatan pelajar berbanding dengan faktor-faktor lain.

Terdapat 6 tema cadangan penambahbaikan yang dicadangkan oleh pelajar. Tema pertama ialah penambahan aktiviti yang aktif dan menarik seperti penganjuran sukan dan e-sport, mempelbagaikan genre muzik dan mengadakan lawatan teknikal. Selain itu, pihak universiti dicadangkan untuk menambah baik infrastruktur sedia ada serta memperbaiki saluran komunikasi agar semua pelajar mendapat maklumat mengenai pelaksanaan aktiviti yang dianjurkan oleh universiti. Perancangan pelaksanaan aktiviti juga hendaklah bersesuaian dengan kalendar akademik pelajar. Ada segelintir 
pelajar mendapati ada kalanya pelaksanaan aktiviti bertindih dengan aktiviti akademik. Cadangan seterusnya adalah sokongan universiti dalam bentuk kewangan serta galakan dan motivasi seperti memberikan kemudahan untuk tinggal di kolej kediaman.

Kajian seperti ini perlu dijalankan pada masa akan datang. Perincian mengikut jenis aktiviti bukan akademik dan perbandingan mengikut jantina terhadap faktor-faktor yang mempengaruhi penglibatan pelajar terhadap aktiviti bukan akademik dapat membantu dalam menjelaskan dan memperincikan lagi penglibatan para pelajar dengan lebih menyeluruh.

\section{Penghargaan}

Kajian ini telah mendapat sokongan dana daripada UTMSPACE, Universiti Teknologi Malaysia di bawah Research Grant Potential Development Fund Vot No. SP-PDF1904.

\section{Rujukan}

Adejompo, F. (2017). Infrastructural facility and the students' academic performance - A critique . Indonesian Journal of Geography 49 (1), 11-16.

Agus, P. (2016). The role of parents' and teachers' supports towards students' involvement in the scouts and the students' entrepreneurial values (Longitudinal studies on students in Jombang, East Java, Indonesia). International Journal of Humanities and Social Science, 6 (1), 61-71.

Al-Ansari, A., Al-Harbi, F., Abdel Aziz, W., Abdel Salam, M., El Tantawi, M. M., \& El Refae, I. (2016). Factors affecting students participation in extra-curricular activities : A comparison between two middle eastern dental schools. The Saudi Dental Journal (28), 36-43.

Aminudin, A. R. (2004). Penglibatan pelajar secara aktif dalam aktiviti kokurikulum dan kesannya ke atas pencapaian akademik. Satu tinjauan di Sekolah Menengah Kebangsaan Pekan Nanas, Pontian. Universiti Teknologi Malaysia.

Braun, V., \& Clarke, V. (2006). Using thematic analysis in psychology. Qualitative Research in Psychology, 3(2), 77-101.

Canossa, A., Martinez, J. B., \& Togelius, J. (2013). Give me a reason to dig minecraft and psychology of motivation. IEEE Conference on Computational Inteligence in Games $(C I G)$. 2. Niagara Falls, ON, Canada: IEEE.

Coulangeon, P. (2018). The impact of participation in extracurricular activities on school achievement of french middle school students: human capital and cultural capital revisited. Oxford University Press.

Curtis, B. \& Curtis, C. (2011). Social research: A practical introduction. SAGE Publications Ltd.

Denault, A. S., \& Guay, F. (2017). Motivation towards extracurricular activities and motivation at school : A test of the generalization effect hypothesis. Journal of Adolescence, (54), 94-103.

Gavin, H. (2013). Thematic analysis: Understanding research methods and statistics in psychology. SAGE Publications Ltd.

Ismail, W. A. W. \& Muhamad, T. A. (2015). Hubungan faktor penghalang terhadap penglibatan pelajar dalam pendidikan jasmani di sekolah menengah. International Conference of Language, Education and Innovation, 22-29.

Jian Xu, (2017). Students' engagement and parents' involvement in extracurricular activities. University of Victoria.

Kardi, N. (2011). Konsep universiti dan aplikasinya di Malaysia. Global Journal Al-Thaqafah 1(1), 43-55.

Kementerian Pendidikan Malaysia. (n.d.). Pelan Pembangunan Pendidikan Malaysia (Pendidikan Tinggi). Retrieved from Ringkasan Eksekutif PPPM 2015-2025: https://bendahari.uthm.edu.my/v2/PPPM/Ringkasan-Eksekutif-PPPM-2015-2025.pdf

Kumar, P. M, \& Aithal, P. S. (October 2019). Importance of time as resource in managing organizations. Proceedings and National Conference on Recent Advances of Technological Innovations in IT, Managements, Education \& Social Sciences ISBN no : 978-81-941751-6-2, 45-52. 
DOI: https://doi.org/10.47405/mjssh.v5i11.559

Lim, E.C. \& Alum, J. (1995). Construction productivity: Issues encountered by contractors in Singapore. International Journal of Project Management, 13(1), 51-58

Mahani, A., \& Suraiya, I. (Jun 2020). Kewangan, jaringan institusi dan teknologi pendorong tingkah laku inovasi pembungkusan usahawan mikro. Malaysian Journal of Sciences and Humanities MJSSH 5(6), 79-90.

Mohd Faizullah, M. (Disember, 2014). Penerapan kemahiran insaniah dalam konteks membina insan berkepimpinan di kalangan pelajar melalui aktiviti kokurikulum di universiti. Batu Pahat, Johor: Fakulti pendidikan teknikal dan vokasional Universiti Tun Hussien Onn, Malaysia.

Meluso, J. A. (2020). Networked miscommunication : the relationship between communication networks, misunderstandings and organizational performance. Michigan,USA: University of Michigan.

Nor, A. R. M. Muhamad, M. R., Jasli, M. F., (2017). Pengaruh pembelajaran sepanjang hayat (PSH) dalam kebolehpasaran lulusan sijil pemasangan elektrik kolej komuniti. Politeknik \& Kolej Komuniti Journal of Lifelong Learning, 1(1), 31-41.

Othman, R. \& Jasni, N. F. A. (2016). Faktor yang mempengaruhi penglibatan pelajar dalam aktiviti kokurikulum di Politeknik Tuanku Sultanah Bahiyah. Politeknik \& Kolej Komuniti Journal of Social Sciences and Humanities, 1(1), 91-100.

Taiwo, B. M. (1998). Maintenance of school infrastructure for productivity. Ilorin: University of Ilorin.

Tews, M. J., Michael, J. W., \& Stafford, K. (2013). Does fun pay? The impact of workplace fun on employee turnover and performances. Cornell Hospitality Quarterly 54(4), 370-382.

Villalobos, A. S., Dulce, A. J., Fontilar, L. J., Gutierrez, D. M., Sawali, R.-a. C., \& Hadge, A.-E. (January 2016). Benefits to co-curricular activities to academic performance of financial and management accounting students. Asia Pasific Journal of Education, Arts and Sciences 3(1), 83-93. 